\title{
"SUYSOS, CABALLERÍAS DE CABALLOS, MUGERES COMO VAN CAUALGANDO...": UN PROYECTO DE PINTURA MURAL PARA EL PALACIO DE LAS DUEÑAS EN 1540
}

\author{
"SUYSOS, CABALLERÍAS DE CABALLOS, MUGERES \\ COMO VAN CAUALGANDO...": A MURAL PAINTING \\ PROJECT FOR LAS DUEÑAS PALACE IN 1540
}

\author{
Juan Antonio Gómez Sánchez \\ Grupo de investigación HUM317: Laraña. España \\ dusares@hotmail.com
}

\begin{abstract}
En este artículo se documenta un proyecto de pintura mural concertado en 1540 por el pintor Diego Rodríguez para doña Inés Portocarrero, destinado a sus casas en la collación de San Juan de la Palma, hoy palacio de las Dueñas. Aunque solo se han conservado las condiciones contractuales de la obra, resulta un testimonio de interés en el panorama pictórico de carácter civil de la primera mitad del siglo XVI hispalense, del que apenas han quedado restos, y viene a incidir en el papel fundamental que jugó la familia Enríquez de Ribera en el patrocinio artístico del periodo.

Palabras clave: Renacimiento español; pintura mural; palacio de las Dueñas; Inés Portocarrero; Diego Rodríguez.
\end{abstract}

This paper documents a mural painting project signed in 1540 by the painter Diego Rodríguez for Doña Inés Portocarrero, destined for her main "casas" in the San Juan de la Palma neighborhood, known today as Las Dueñas Palace. Although only the contractual conditions for the work have been preserved, it's an interesting testimony of the non-religious Sevillian painting from the first half of the $16^{\text {th }}$ century, which have left a scarcity of traces, and confirms the fundamental role played by the Enríquez de Ribera family in the artistic patronage of the period. dríguez.

Keywords: Spanish Renaissance; mural painting; Dueñas Palace; Inés Portocarrero; Diego Ro-

En la historia del arte sevillano del Renacimiento, el capítulo de la pintura mural de carácter civil continúa siendo uno de los menos conocidos. Ligado por definición a la arquitectura, hoy es un aspecto irremediablemente perdido al que solo es posible acercarnos a partir de unos pocos restos mutilados o desvirtuados $\mathrm{o}$, indirectamente, a través de las fuentes documentales, casi siempre muy parcas 
en las descripciones de las obras contratadas ${ }^{1}$. Con este propósito damos a conocer un contrato notarial firmado por el pintor Diego Rodríguez, por el que se comprometía a realizar una obra de pintura mural de notables proporciones e inusual programa iconográfico para uno de los miembros de la familia de los Enríquez de Ribera, familia que a lo largo del siglo XVI hispalense estuvo en todo momento en vanguardia de los cambios de gusto artístico que se sucedieron en la ciudad, cuando no se adelantó a ellos importando piezas directamente de Italia.

La personalidad de don Fadrique Enríquez de Ribera, primer marqués de Tarifa, y los ciclos de pintura mural que promovió en sus casas principales de la collación de San Esteban (Casa de Pilatos) ocupan en este contexto un lugar privilegiado en la introducción en Sevilla de las formas clásicas en la primera mitad de la centuria ${ }^{2}$. No obstante, no fue don Fadrique el único miembro de la familia, ni el primero, que demostró interés por las decoraciones murales pintadas. Aunque apenas han sobrevivido unos pocos restos, también las casas familiares de la collación de San Juan de la Palma, hoy palacio de las Dueñas, residencia de su hermano Fernando Enríquez de Ribera, fueron en su día decoradas con pinturas murales ${ }^{3}$. Dentro del recinto actual del palacio se conservan fragmentos, aún sin documentar, en las galerías bajas y altas del patio principal (Figura 1), en la baja

${ }^{1}$ En este sentido, resulta sintomático que la pintura mural apenas haya encontrado hueco en los estudios generales dedicados a la historia del arte sevillano del Renacimiento, aunque sí atrajo el interés de estudios pioneros como el de GESTOSO Y PÉREZ, José: "La casa sevillana en los siglos XIV, XV y XVI", en Curiosidades antiguas sevillanas, segunda serie. Sevilla, 1910, pp. 149-179, esp. pp. 167-171; o el que Vicente Lleó dedicó al humanismo sevillano. Cfr. LLEÓ CAÑAL, Vicente: Nueva Roma: mitología y humanismo en el Renacimiento sevillano. Sevilla, 1979, pp. 41-44. Este autor, ya centrado en la Casa de Pilatos, ha dedicado algunos estudios posteriores a los murales de la casa. Por su parte, Juan Miguel Serrera dedicaría un artículo específico a las pinturas del convento de Santa Inés, insertándolas en un contexto más amplio. SERRERA, Juan Miguel: "La pintura mural sevillana del siglo XVI y su influencia en México", en Actas de las I Jornadas de Andalucía y América. T. II. Huelva, 1981, pp. 323-336.

${ }^{2}$ LLEÓ CAÑAL, Vicente: Nueva Roma..., op. cit., pp. 20-ss; LLEÓ CAÑAL, Vicente: La Casa de Pilatos. Madrid, 1998, pp. 23-41; y LLEÓ CAÑAL, Vicente: La Casa de Pilatos: biografia de un palacio sevillano. Sevilla, 2017, pp. 43-92.

${ }^{3}$ Sobre el palacio de las Dueñas, hoy propiedad de la Casa de Alba, ver FALCÓN MÁRQUEZ, Teodoro: "Palacio de las Dueñas", Reales Sitios, número dedicado a Sevilla, 1976, pp. 133-136; FALCÓN MÁRQUEZ, Teodoro: "La decoración de los palacios sevillanos del siglo XVI: Estudio iconográfico e iconológico", Cuadernos de Arte e Iconografía, II, 3, 1989, pp. 282-287; FALCÓN MÁRQUEZ, Teodoro: "El palacio de las Dueñas: sus orígenes. La escritura de compra-venta de 1496", Laboratorio de Arte, 10, 1997, pp. 195-121; FALCÓN MÁRQUEZ, Teodoro: El Palacio de las Dueñas y las casas-palacio sevillanas del siglo XVI. Sevilla, 2003; ALBENDEA RUZ, Esther: "La primera cubierta renacentista del palacio de las Dueñas de Sevilla", Quiroga, 1, 2012, pp. 12-19; ALBENDEA RUZ, Esther: "El palacio de las Dueñas de Sevilla: Las techumbres de la época de Catalina 
del llamado del Aceite y en la antecapilla, que sugieren dadas sus divergencias de estilo una sucesión de campañas decorativas ${ }^{4}$, pero ninguna de estas revistió la importancia de la concertada por Diego Rodríguez en 1540, llegara a realizarse o no finalmente.

A diferencia de la falta de documentación sobre las pinturas murales de Dueñas, disponemos de alguna información sobre las obras de pintura llevadas a cabo en las techumbres de carpintería del palacio. Así, aunque por lo temprano de la fecha es probable que todavía se inscribiera dentro de la tradición mudéjar o gótica, ya en 1501, por orden de doña Catalina de Ribera $(\dagger 1505)^{5}$, quien había adquirido las casas en 1496, el pintor Gonzalo Díaz había realizado cierta obra de pintura y dorado, sin concretar, en las casas de don Fernando, su hijo ${ }^{6}$. Pero en 1516, al concertar Alonso de León con un criado de Fernando Enríquez la pintura de un zaquizamí de molduras para dichas casas, ya se especificaba el carácter "romano" de los motivos decorativos".

de Ribera", Laboratorio de Arte, 25, 2013, pp. 219-234; y LLEÓ CAÑAL, Vicente y ASÍN, Luis: El palacio de las Dueñas. Gerona, 2016.

${ }^{4}$ Aunque muy fragmentarios, los restos murales comprenden decoraciones de carácter mudéjar en el ángulo noroeste de la galería alta del patio principal, cresterías góticas en el muro oeste del patio del Aceite, cresterías también góticas pero más evolucionadas, con atisbos renacientes y algún fragmentario panel de grutescos en la galería alta del patio principal y la antecapilla, y columnas con capiteles compuestos que sostienen entablamentos de carácter clásico en las galerías bajas del patio principal. Excepto en el último caso, que pudiera ser cercano a las fechas en las que se firmó el contrato que estudiamos, se trata de decoraciones murales estilísticamente anteriores. Sobre estas, ver FALCÓN MÁRQUEZ, Teodoro: "La decoración de los palacios...", op. cit., p. 286; FALCÓN MÁRQUEZ, Teodoro: El Palacio..., op. cit., pp. 85, 93, 116 y 120; y LLEÓ CAÑAL, Vicente y ASÍN, Luis: El palacio de las Dueñas, op. cit., p. 56.

${ }^{5}$ Sobre su patronazgo artístico, ver ARANDA BERNAL, Ana: "Una Mendoza en la Sevilla del siglo XV. El patrocinio artístico de Catalina de Ribera", Atrio, 10-11, 2005, pp. 5-16.

${ }^{6}$ GESTOSO Y PÉREZ, José: Ensayo de un diccionario de los artífices que florecieron en Sevilla desde el siglo XIII al XVIII inclusive. T. III. Sevilla, 1909, p. 300. La obra de pintura de Gonzalo Díaz correspondería quizá a alguno de los artesonados mudéjares de la época de Catalina de Ribera aún conservados en el palacio. Sobre estos, cfr. ALBENDEA RUZ, Esther: "El palacio de las Dueñas...", op. cit., pp. 219-234.

7 MURO OREJÓN, Antonio: "Pintores y doradores", en Documentos para la Historia del Arte en Andalucía (en adelante, D.H.A.A.). T. VIII. Sevilla, 1935, p. 31. Recientemente, el zaquizamí pintado por Alonso de León en 1516 ha sido identificado con el techo de carpintería de la sala Cuadrada de la planta baja, decorado con paneles de grutescos. Cfr. ALBENDEA RUZ, Esther: "La primera cubierta renacentista...", op. cit., pp. 12-19; y LLEÓ CAÑAL, Vicente y ASÍN, Luis: El palacio de las Dueñas, op. cit., p. 54. Sobre el término "romano" en el arte español del siglo XVI, ver ÁVILA, Ana: Imágenes y símbolos en la arquitectura pintada española (1470-1560). Barcelona, 1993, pp. 78-79, quien señala 
Respecto a la obra que nos ocupa, pueden albergarse ciertas dudas sobre su realización material puesto que, como ocurre en otras ocasiones en los legajos del oficio IX protocolizados por estas fechas, los folios correspondientes al contrato notarial quedaron en blanco, aunque al final del documento constan las firmas del pintor y de los escribanos que actuaron como testigos, si bien no aparece ninguna firma que testificara en nombre de la comitente ${ }^{8}$. Pero hay que tener en cuenta que el hecho de que quedara sin escribir no resulta excepcional en los documentos notariales del periodo. Así sucede en algunos de los contratos de pintura, carpintería y albañilería firmados en el oficio VI para la Casa de Pilatos, que sí llegaron a realizarse efectivamente ${ }^{9}$.

Esta circunstancia también nos impide conocer algunos detalles de la obligación firmada en 1540 en materia de plazos, precio o fianzas de la obra, y también, de forma explícita, el destino concreto para el que fue contratada, por cuanto las condiciones, que sí aparecen transcritas en un folio suelto, se limitan a señalar las

su temprana aparición en el contrato para un retablo levantino en 1506. En Sevilla, el término consta por vez primera en 1510 en el concierto de la obra de pintura de una tribuna para la iglesia de San Marcos, aunque los grutescos habían hecho su aparición en el arte local unos años antes, al menos desde algunas obras realizadas por Niculoso Pisano en 1504. Para el contrato de la tribuna de San Marcos, ver MURO OREJÓN, Antonio: "Pintores y doradores", op. cit., pp. 21-25.

8 AHPS (Archivo Histórico Provincial de Sevilla), sección Protocolos Notariales, leg. 17494, oficio IX, 1540, libro 1, f. 687 (ver Apéndice documental). El contrato tampoco aparece fechado, pero los documentos anterior y posterior lo están el miércoles 3 de marzo de 1540. Hay que reseñar que pocos días después, el 18 de ese mismo mes, el pintor Andrés Martín, colaborador ocasional de Diego Rodríguez, y como él especializado en pintura sobre muro y tabla, firmó ante el mismo escribano un nuevo concierto de pintura. El cuerpo del documento quedó también en blanco, excepto el encabezamiento "Pabto de pintura/ Andrés Martín", constando al final su firma junto a la de los pintores Juan de Zamora y Alonso Pérez (I), probablemente sus fiadores, y los escribanos Alfonso de Baena, Juan de Vergara y Juan de Velarte. AHPS, sección Protocolos Notariales, leg. 17494, oficio IX, 1540, libro 1, f. 829. Desconocidos el carácter y destino de esta obra, no hay que descartar que Martín colaborase con Diego Rodríguez, o que lo sustituyera, en la obra de pintura para doña Inés Portocarrero.

${ }^{9}$ El carácter incompleto de estos documentos ha tenido como consecuencias bibliográficas el que no sea posible en algunos casos establecer el ámbito concreto al que las obras fueron destinadas dentro del recinto de la Casa de Pilatos, y también el que se haya considerado a todos los pintores firmantes de un documento dado como comprometidos a realizarlas, cuando en realidad firmaron tanto los obligados como sus fiadores. Es el caso, como ejemplo, de Alejo Fernández, que muy posiblemente actuó como fiador de su hijo Sebastián Alexos y de otros pintores en 1537, no como artista concertado a realizar la obra de pintura. Sobre este problema, GÓMEZ SÁNCHEZ, Juan Antonio: Alejo Fernández y la pintura sevillana del primer tercio del siglo XVI. Tesis doctoral inédita. Sevi1la, 2015, pp. 400-402. 
"casas de la morada" de doña Inés Portocarrero y Cárdenas, hija de los señores de Moguer y de Villanueva del Fresno, y viuda desde 1522 de don Fernando Enríquez de Ribera $-\mathrm{y}$ en consecuencia, cuñada de don Fadrique $-^{10}$. Aunque hay que tener en cuenta que la familia poseía un elevado número de propiedades, tanto en Sevilla como fuera de ella, parece lógico pensar que el documento se refiera a las casas principales de esta rama familiar en la collación de San Juan de la Palma, ubicadas en el hoy conocido como palacio de las Dueñas, donde residía doña Inés con sus hijos menores -a pesar de los litigios que sostuvo con su hijo Per Afán al menos hasta $1537^{11}-$. Más, si tenemos en cuenta que el enorme muro descrito en el contrato, aunque quizá modificado o reconstruido posteriormente, todavía puede identificarse con uno de los conservados en el recinto de Dueñas. Con todo, el encargo de doña Inés Portocarrero es interesante también por lo que supone como continuidad de la labor promotora de otros miembros de la familia, viniendo a modificar, aunque de forma puntual, la penuria documental que rodea las obras realizadas en las casas de la collación de San Juan de la Palma a lo largo de su historia.

En cualquier caso, si tenemos en cuenta la rareza de los ejemplos conservados, y el laconismo de la mayor parte de la documentación hasta el momento publicada referida a la pintura mural sevillana de carácter laico de la primera mitad del siglo XVI, el proyecto de decoración pintada para doña Inés adquiere cierta importancia, equiparable a las pinturas contratadas un año antes por el mismo

${ }^{10}$ Sobre Inés Portocarrero y Cárdenas $(† 1546)$, cfr. ORTIZ DE ZÚÑIGA, Diego: Anales eclesiásticos y seculares de la muy noble y muy leal ciudad de Sevilla, metrópoli de la Andalucía. T. III. Madrid, 1796, p. 328; y GONZÁLEZ MORENO, Joaquín: Catálogo de documentos sevillanos del Archivo Ducal de Alcalá de los Gazules. T. I. Sevilla, 1976, pas$\mathrm{sim}$. Hay que recordar que tras la muerte sin descendencia legítima de don Fadrique el año anterior de 1539, el mayordomazgo y las posesiones de este, entre ellas la propia Casa de Pilatos, vinieron a parar en su sobrino Per Afán de Ribera, segundo marqués de Tarifa y futuro primer duque de Alcalá y virrey de Nápoles (1558), hijo de don Fernando y doña Inés y con el tiempo brillante continuador de la tradición de mecenazgo artístico de la familia. Cfr. LLEÓ CAÑAL, Vicente: "El jardín arqueológico del primer Duque de Alcalá", Fragmentos, Revista de Arte, 11, 1987, pp. 21-32. Fallecido este último, le sucedería otro hijo de Inés Portocarrero, el segundo duque de Alcalá don Fernando Enríquez de Ribera. En otro ámbito, Inés Portocarrero demostraría un carácter decidido al hacerse cargo tras la muerte de su marido de la gestión de los asuntos de la hacienda familiar, como antes que ella había hecho Catalina de Ribera, en particular de las almonas a las que los Enríquez de Ribera debían gran parte de su fortuna. Una administración que la llevaría a afrontar una interminable serie de pleitos contra los marqueses de Ayamonte, con mercaderes alemanes, las ciudades de Sevilla y Cádiz o el duque de Béjar, entre otros.

${ }^{11}$ Quizá no sea una coincidencia que la obra de pintura que nos ocupa fuese encargada precisamente en 1540, un año después de que su hijo Per Afán se hiciera cargo de la herencia de su tío. Según la documentación, aparentemente en estas fechas habían quedado atrás los pleitos sostenidos por ambos, madre e hijo. 
artista para la Casa de Pilatos, que constituyen aún en su incompleto estado actual el más importante testimonio de los ciclos murales de carácter profano que se pintaron en Sevilla en la primera mitad de la centuria.

Según las condiciones, probablemente escritas por el pintor Alonso Pérez $\mathrm{I}^{12}$, quien daría inicio a una puja a la baja valorando la obra en unos iniciales 20.000 maravedís, Diego Rodríguez se obligaría a pintar una pared de 450 varas "en toda quadra" que salía a la huerta principal, a espaldas de las casas de doña Inés. Estas medidas permiten identificar con cierta seguridad el muro sobre el que se desplegaría la decoración pintada con el que aún hoy, encalado y enteramente cubierto por enredaderas, cierra el edificio del palacio de las Dueñas en el sector norte ${ }^{13}$ (Figura 2), si bien es posible que el muro actual sea una reconstrucción al menos parcial del original, puesto que en un informe realizado tras los efectos del terremoto de Lisboa de 1755 se hacía constar la necesidad de "componer los entresuelos que lindan a el jardín y derribar los cielos rasos, como también la pared que hace testero a dicho cuarto que cae a dicho jardín"14. Este muro, que aparece en un plano del palacio levantado en 1756, da al jardín que en esta última fecha era conocido como jardín del cuarto segundo, la antigua huerta de la época de doña Inés (Figura 3). Todavía hoy el muro cierra un sector de estrechas dependencias de servicio dividido en dos plantas y un entresuelo, hecho que podría explicar la división en tres registros, y no dos, de la decoración pictórica exterior, pero no hay que descartar que dichos entresuelos, si no son aún posteriores, correspondan más bien a la extensa campaña de renovaciones realizadas por orden de don Fernando Enríquez de Ribera y Portocarrero en 1571-1572 $2^{15}$. También puede plantearse la alternativa de que pudiera tratarse del muro, hoy interior, inmediatamente paralelo a este.

${ }^{12}$ Uno de los artistas más activos en el campo de la pintura decorativa sobre muro y tabla, documentado en Sevilla entre 1510 y 1547, fecha en la que consta ya como difunto. En el presente artículo usamos el numeral I para distinguirlo de su hijo del mismo nombre y apellido, también pintor.

${ }^{13}$ A pesar de la expresión "en toda quadra", es difícil estar seguros si las 450 varas se refieren específicamente a varas o a varas cuadradas, que corresponderían a $376,15 \mathrm{o}$ 314,41 metros cuadrados respectivamente. Según las medidas que tomamos in situ con ayuda del personal del palacio, las medidas del muro que da al jardín norte son en la actualidad 33,40 metros de largo por 11 de alto; o lo que es lo mismo, 367,40 metros cuadrados. Teniendo en cuenta que las medidas que constan en el concierto se matizan con un "poco más o menos", y los más que probables cambios en la altura del nivel del suelo de tierra del jardín a lo largo de los siglos, estas se corresponden con las 450 varas cuadradas reseñadas en las condiciones.

${ }^{14}$ Citado en FALCÓN MÁRQUEZ, Teodoro: El Palacio de las Dueñas..., op. cit., p. 105.

${ }_{15}$ Documento transcrito parcialmente en FALCÓN MÁRQUEZ, Teodoro: $\mathrm{El} \mathrm{Pa}$ lacio de las Dueñas..., op. cit., pp. 145-152. Sobre estas renovaciones ver asimismo LLEÓ CAÑAL, Vicente y ASÍN, Luis: El palacio de las Dueñas, op. cit., pp. 67-87. 
Esta extensa superficie había de dividirse en tres registros superpuestos, separados por entablamentos descritos minuciosamente según una terminología que, si no responde a una tradición común, parece derivar directamente del tratado de Diego de Sagredo ${ }^{16}$. Los "cuerpos" superpuestos definidos por los entablamentos se articulaban horizontalmente en una serie de compartimentos por medio de pilares -de los que no se olvida mencionar basas y capiteles- en cuyo fuste se inscribían unos "rredondos" - a semejanza de los que aparecen en la portada genovesa de la Casa de Pilatos, contratada en 1528-.

En el registro alto habrían de pintarse una serie de "ordenanzas", sobre las que en el momento del contrato no se tenía todavía claro si debían ser cuatro o seis, sucesivamente de mercenarios suizos, de "caballerías de caballos", y de mujeres "como van caualgando con sus cauallos y palafrenes" 17 , quedando el resto de ellas aún por concretar, aunque se especificaba que las figuras debían ser de tamaño natural "por causa del altura". En este registro superior, que revela un gusto cortés y nobiliario en la representación ordenada de soldados, caballerías (jinetes) y damas a caballo, sorprenden en particular estas últimas, en cuya elección pudo quizá influir el sexo de la comitente. Nada habituales en el arte español del siglo $X V I^{18}$, es posible que sus precedentes visuales en el arte europeo haya que buscarlos en particular en la tapicería flamenca, en la que por esas décadas no es infrecuente la aparición de damas de la corte a caballo en diversos contextos, siempre de un marcado cariz aristocrático ${ }^{19}$.

${ }^{16}$ Así, los términos entablamento, cornisa, nacela, dentellón o moldura, utilizados en las condiciones del contrato, son los mismos ya empleados en las Medidas del Romano, primera edición, Toledo, 1526.

17 Hasta las modificaciones introducidas en las sillas femeninas de cabalgar a finales de esa centuria, la presencia de palafreneros que ayudaran al gobierno de las monturas era en la práctica poco menos que inexcusable dada la dificultad de la cabalgadura lateral, "a mujeriegas", exigida a las damas.

${ }_{18}$ Mucho más tarde, hacia 1580 y al otro lado del Atlántico, damas a caballo formarían parte de la decoración mural de uno de los salones de la Casa del Deán en Puebla, pero en esta ocasión se adornarían de un significado alegórico -como representación de las sibilas de la tradición grecorromana cristianizada, allí excepcionalmente pintadas como amazonas- que debemos descartar en el contexto del proyecto mural sevillano. Sobre estas, ver VON KÜGELGEN, Helga (ed.): Profecía y triunfo. La casa del Deán Tomás de la Plaza. Facetas plurivalentes. Madrid, Frankfurt y México, 2013.

${ }_{19}$ Así, en la perdida serie de tapices de la genealogía de la Casa de Orange-Nassau, hacia 1529-1531, conocida hoy por los dibujos preparatorios de Bernard van Orley, las diferentes generaciones de las damas de la familia aparecían a caballo acompañando a sus respectivos esposos. En un tono más informal, se encuentran también en la serie conocida como las "Cazas de Maximiliano", según cartones del mismo artista (editio princeps en el Museo del Louvre y múltiples versiones posteriores), hacia 1528-1533, en la que la frecuente aparición de damas a caballo se ha buscado explicar atribuyendo su encargo a una mujer del entorno imperial de Carlos V, quizá María de Hungría; en los tapices de los 
Relativamente menos inusuales en la pintura española del Renacimiento, también llaman la atención los "suysos" de la primera ordenanza. Modelos -y rivales encarnizados- del lansquenete en el mercado del mercenario, no hay constancia de su presencia en España en la época del emperador Carlos -quien sí contaría con mercenarios alemanes en sus campañas europeas-, pero según testimonio del cronista Hernando del Pulgar un contingente de suizos habrían servido a los Reyes Católicos en la guerra de Granada, donde décadas antes habían estado presentes Pedro Enríquez de Quiñones y quizás también Fernando Enríquez de Ribera - por entonces todavía niño-, respectivamente suegro y marido de doña Inés ${ }^{20}$. La visión de los suizos de Hernando del Pulgar, que los tiene por devotos y buenos cristianos que solo participan en las guerras que consideran justas, contrasta vivamente con la imagen, mezcla de admiración y horror -el prototipo de chico malo de la época, en palabras de Chastel ${ }^{21}$ - que se tendría tanto del mercenario suizo (reisläufer) como del alemán (lansquenete) en el periodo en el que fue contratada la pintura mural que estudiamos, una imagen que, unida a su extravagante gusto en el vestir, atraería vivamente a los artistas europeos del momento no solo en las propias Suiza y Alemania ${ }^{22}$ (Figura 4).

En el registro medio, igualmente subdividido en unidades cuadrangulares por medio de pilares, Rodríguez se obligaba a realizar una serie de paneles al romano, diferentes entre sí, en los que habría de pintar el repertorio habitual del grutesco renacentista, entre el que el autor de las condiciones escoge mencionar arpías, niños, golfines (delfines), bestiones "y otras diferencias que el rromano trae consigo". Unos grutescos que no debieron diferir mucho de los que encontramos, más reducidos en dimensiones y repintados, en los paneles que alternan

\footnotetext{
"Meses de Lucas", hacia 1535, en los que significativamente son las damas de la corte las que cabalgan monturas, nunca las mujeres del campo; o en diversos ejemplares de colgaduras aisladas. Sobre estas series, ver CAMPBELL, Thomas P. y otros: Tapestry in the Renaissance. Art and magnificence. Nueva York, 2002, pp. 299-300, 302 y 329-338.

20 "Uinieron assi mesmo a seruir al rey y a la reyna vna gente que se llama los Suyços, naturales del reino de Sueça [sic], que es en la alta Alemaña. Estos son hombres belicosos, y pelean a pie, y tienen proposito de no boluer las espaldas a los enemigos... son gentes que andan a ganar sueldo por las tierras y ayudan en las guerras que entienden que son mas justas...". DEL PULGAR, Hernando: Chrónica de Muy Altos, y esclarecidos Reyes Cathólicos Don Hernando y Doña Ysabel de gloriosa memoria (se cita por la edición de Zaragoza, Juan Millán, 1567, f. cxiii). Sobre el empleo de mercenarios suizos por parte de la monarquía hispánica en épocas posteriores, a partir del reinado de Felipe II, ver CALLEJA LEAL, Guillermo (coord.): Presencia suiza en la milicia española, monográfico de la Revista Internacional de Historia Militar, 95, Madrid, 2017.

${ }^{21}$ CHASTEL, André: El Saco de Roma, 1527. Madrid, 1986, p. 122.

22 VON SEGGERN, Birgit: Der Landsknecht im Spiegel der Renaissancegraphik un 1500-1540. Bonn, 2003 (accesible en línea en http://hss.ulb.uni-bonn.de/2003/0285/0285. pdf; consultado el 25-9-2017).
} 
con escenas bíblicas y figuras de santos en el claustro del Herbolario del convento de Santa Inés, convento para el que Diego Rodríguez se comprometió a realizar una obra de pintura indeterminada en agosto del mismo año ${ }^{23}$.

Menos usuales que el registro medio, con sus conspicuas decoraciones al romano, eran las condiciones estipuladas para el bajo, en el que debía pintarse una serie de "lexos y montaña" 24 en compartimentos separados asimismo por pilares, y situados sobre un basamento con cenefas al romano, que sustentaría visualmente la obra. Situados al nivel del espectador, tales paisajes representarían una función de fondo o telón fingido, de contrapunto pero también prolongación de la huerta en la que se situaba el muro, planteando, al menos idealmente, un diálogo entre arte y naturaleza, naturaleza real y pintada. No obstante, la breve descripción que ofrece el documento del carácter de estos paisajes ya nos informa de los límites de este juego "ilusionista": el punto de vista presumiblemente elevado y los "lexos y montaña" aluden, más que a una representación especular de la huerta, a los convencionalismos del paisaje en el arte del periodo. Aunque quisiéramos buscar su inspiración en testimonios de la literatura clásica, en particular en Vitrubio, quien señalaba su conveniencia en la decoración mural -en perjuicio de la pintura de grutescos ${ }^{25}-$, en el aspecto formal debieron depender de pinturas,

${ }^{23}$ AHPS, sección Protocolos Notariales, leg. 17495, oficio IX, 1540, libro 2, registro 34 , s. f. El carácter de esta obra se nos escapa al aparecer una vez más los folios del documento en blanco y, en este caso, sin las condiciones, pero podría corresponder a alguna de las decoraciones murales que aún se conservan en los claustros, quizá más a los fragmentos de crestería pintada de las galerías superiores del claustro del Noviciado que a los del extenso ciclo del claustro del Herbolario, demasiado fragmentarios en el primer caso, y repintados en el segundo, como para establecer conclusiones definitivas sobre su autoría. Juan Miguel Serrera fechó los restos murales del claustro del Noviciado hacia 1545, basándose en las concordancias formales que encontraba entre estos y los elementos decorativos de la galería de Hombres Ilustres de la Casa de Pilatos, y apuntando la posible autoría de Diego Rodríguez, una hipótesis que, salvo en un leve ajuste de fechas, habría que tener aún más en cuenta a la luz del nuevo documento. Cfr. SERRERA, Juan Miguel: "La pintura mural sevillana...", op. cit., pp. 323-336.

${ }^{24}$ Quizá haya que interpretar "montaña" en su significado original de masa de vegetación, no en el de relieve. Cfr. GARCÍA FERNÁNDEZ, Jesús: "De la percepción del hecho montañoso: en torno a las palabras: «monte-montes» y «montaña»", Estudios Geográficos, 51, 199-200, 1990, pp. 431-432.

${ }^{25}$ Contemporáneamente a las pinturas sevillanas, Serlio, al mismo tiempo que se oponía a la rotura visual de los edificios con personajes fingidos y paisajes en los exteriores, hace una significativa excepción y recomienda la pintura de paisajes "dappresso e di lontano" en los muros de "loggie intorno a giardini et ai cortili". SERLIO, Sebastiano: Regole generali di architettura di Sabastiano Serlio bolognese sopra le cinque maniere degli edifici, Libro Quarto. Venecia, 1537, cap. XI, p. LXIX vto. 
grabados y tapices italianos y flamencos ${ }^{26}$. En este sentido, parece oportuno señalar cómo en la inédita carta de aprendizaje firmada por Alonso Rama, natural de Arjona, con el propio Diego Rodríguez unos años antes, este se comprometió a enseñarle a "fazer e dar quenta de una sarga de figuras e otra sarga de bosque bien e cunplidamente" 27 , denominación que viene a demostrar su carácter sustitutivo de las tapicerías de arboleda flamencas, tan difundidas en los inventarios contemporáneos españoles y sevillanos, de las que la propia Inés Portocarrero poseyó algunos ejemplares ${ }^{28}$. Tampoco en la decoración mural sevillana el paisaje era desconocido, por cuanto ya en 1511 el pintor Francisco Ximénez había contratado una obra de pintura en el patio de las casas del veinticuatro Juan de Torres en la que debía realizar en las "fresas" "unos lexos buenos e de buen arte en que vaya cielo e tierra e agua e árboles e verduras e... otras cosas que se contienen para ellos", si bien en este caso no se trataba de paisajes independientes por cuanto servían de fondo a escudos de $\operatorname{armas}^{29}$. Tanto las sargas de bosque que

${ }^{26}$ No son escasos los precedentes italianos con un esquema similar de una estructura arquitectónica con pilastras, abierta a paisajes, como en la desaparecida decoración pintada por Pinturicchio en la loggia del Belvedere vaticano, la loggia de la Casa de los Caballeros de Rodas o la Casina del Cardenal Bessarione. En España, hay necesariamente que recordar las vistas de arboleda puntuadas por pilastras de la antesala capitular de la catedral de Toledo, realizadas en 1511 por un equipo de pintores siguiendo probablemente las trazas de Juan de Borgoña; un esquema este último que Isabel Mateo Gómez interpretó como alusión al "huerto cerrado" mariano. Cfr. MATEO GÓMEZ, Isabel: "Sugerencias sobre el programa iconográfico de la sala capitular de la catedral de Toledo", Archivo Español de Arte, 259-260, 1992, pp. 371-376. También, MUNTADA TORRELLAS, Ana: "Luis Medina y la pintura del zaguán del cabildo nuevo de la catedral de Toledo", en El Mediterráneo y el Arte Español: Actas del XI Congreso del CEHA. Valencia, 1996, pp. 104-107.

${ }^{27}$ Firmada el 2 de septiembre de 1534. AHPS, sección Protocolos Notariales, leg. 2271, oficio IV, 1534, libro único, registro 38, s. f. Ese mismo día el pintor firmaría la carta de aprendizaje de Pedro Márquez, natural de Ronda, por un año (ibidem), mientras que el 21 de noviembre recibiría por aprendiz a Pedro Navarro, de Sevilla, por seis años (ibidem, registro 52, s. f.).

${ }^{28}$ Los paños de verduras y antepuertas de boscajes que constan en los inventarios de su marido, fallecido entonces, y de ella misma, fechados en 1522. Citados por URQUÍZAR HERRERA, Antonio: Coleccionismo y nobleza. Signos de distinción social en la Andalucía del Renacimiento. Madrid, 2007, p. 121. Entre otros muchos ejemplos posibles, también merece la pena recordar los citados en el inventario realizado en las casas de don Fadrique Enríquez de Ribera en 1531. Cfr. GONZÁLEZ MORENO, Joaquín: "Don Fabrique Enríquez de Ribera”, Archivo Hispalense, XXXIX, 122, 1963, pp. 201-280, p. 257.

${ }_{29}$ GESTOSO Y PÉREZ, José: "La casa sevillana...”, op. cit, pp. 167-169; y LLEÓ CAÑAL, Vicente: Nueva Roma..., op. cit. pp. 41-44. A su vez, aunque el paisaje adquiría cierta importancia en las posteriores escenas pintadas en las galerías laterales del patio bajo del Crucero de los Alcázares, este carece también de un carácter independiente al ser siempre un paisaje habitado por las figuras que definen cada una de las escenas. Sobre 
Rodríguez enseñaba a pintar como los "lexos" de las casas de doña Inés testimonian la temprana existencia de un mercado y hasta cierto punto de unos nuevos especialistas, si no de un nuevo género, antes incluso que el término paisaje apareciese en lengua castellana.

En la decoración mural encargada por doña Inés Portocarrero se conjugaban como hemos podido ver varios planos de discurso. El enmarcamiento de arquitectura pintada garantizaba la unidad visual de un conjunto de elementos superpuestos dispares. La fórmula era bien conocida en la pintura italiana de la segunda mitad del siglo XV, tanto en conjuntos religiosos como profanos, siendo al mismo tiempo un método lógico de separación entre episodios diferentes dentro de una narración pero también una manera eficaz de articular el muro e imponer un orden racional a un espacio neutro como era la pared sobre la que se desarrollaba. Aunque la decoración concertada por Diego Rodríguez se inscribía en esta larga tradición, su peculiaridad estribaba en presentar "episodios" que, si bien diferenciados -suizos, jinetes, damas a caballo- y separados regularmente por pilares, se desarrollarían de forma más o menos continua a lo largo del muro, a manera de friso - una continuidad que imaginamos pudo ser aún más evidente en los paisajes del registro bajo-. El precedente visual de este esquema "procesional" pudo estar en el espléndido ciclo de los Triunfos de César de Mantegna (Hampton Court), pintados en Mantua hacia 1486-1505 y difundidos a principios del XVI a través de series grabadas que el pintor responsable del proyecto sevillano pudo conocer; pero también, de una forma más cercana, en el mundo de la fiesta renacentista, en particular en las entradas reales. Aunque la pintura carecía de un contenido histórico preciso, no dejaría de evocar en cierta medida las entradas de Carlos V e Isabel de Portugal en Sevilla unos años antes con motivo de su boda, fiesta que Inés Portocarrero, ya viuda por entonces, hubo de conocer y en la que había tenido un papel de cierta relevancia su cuñado don Fadrique. Por otra parte, cierto carácter militar -en particular en la primera ordenanza de "suysos"- no dejaría de tener alguna resonancia en las casas de la familia: había sido Fernando Enríquez, marido de Inés Portocarrero, el responsable de acabar con la revuelta comunera en Sevilla, siendo nombrado en 1521 capitán general de Andalucía por Carlos $\mathrm{V}$ en reconocimiento.

Aunque su presencia en Sevilla solo se documenta a partir de unos años más tarde de dicha entrada, Diego Rodríguez pudo estar igualmente familiarizado con las posteriores series grabadas conmemorativas de entradas regias, en particular

estas, ver BACEIREDO RODRÍGUEZ, M. ${ }^{\text {a }}$ Isabel y BACEIREDO RODRÍGUEZ, Daniel: "Las pinturas murales de las galerías perimetrales del Patio bajo del Crucero. Aproximación al estudio iconográfico", Apuntes del Real Alcázar de Sevilla, 13, 2012, pp. 56-89; y BACEIREDO RODRÍGUEZ, M. ${ }^{a}$ Isabel: "Intervenciones en las pinturas murales renacentistas de la galería central del Patio bajo del Crucero", Apuntes del Alcázar de Sevilla, 16, 2015, pp. 175-217. 
con las diversas series abiertas de la celebrada en Bolonia en 1530 con motivo de la coronación del emperador Carlos. No en vano, el recurso a fuentes gráficas, generalizado en el siglo XVI español, está perfectamente documentado en el caso de Diego Rodríguez: ya Angulo señaló la derivación de los Triunfos de la Casa de Pilatos de una serie grabada poco antes (1537), entonces atribuida a Pieter Coecke van Aelst pero en la actualidad asignada al anónimo Monogramista ATP $^{30}$.

Dejando a un lado las extraordinarias dimensiones del conjunto y la compartimentación de la superficie pintada en tres niveles superpuestos en altura, sin precedentes hasta el momento conocidos en el ámbito hispalense, la novedad del proyecto de pintura mural para las casas de doña Inés radicaba en su iconografía: conocidos los conjuntos de carácter religioso (Santa Inés), alegórico-mitológico (triunfos de Pomona, Jano, Ceres y Flora, en la Casa de Pilatos) o histórico (hombres ilustres de la Antigüedad de la Casa de Pilatos, o las desaparecidas batallas de Carlos V contra los luteranos en el palacio de Altamira), no se tenía hasta el momento noticia en la Sevilla de la primera mitad del XVI de conjuntos pictóricos figurativos caracterizados por la ausencia de un contenido simbólico explícito. Aunque naturalmente el proyecto de pintura mural que había de pintarse en el muro que daba a la huerta de doña Inés Portocarrero tendría también una función honorífica, de prestigio y rango social para la familia ${ }^{31}$, tanto su localización en un ámbito que suponemos más o menos reservado, en la trasera de las casas ${ }^{32}$, como la ausencia de un mensaje histórico, mitológico o alegórico, incidirían en el carácter puramente decorativo, respondiendo más bien a un deseo de delectación,

${ }^{30}$ ANGULO ÍNIIGUEZ, Diego: La mitología y el arte español del Renacimiento. Madrid, 1952, pp. 29-40. Vicente Lleó, no obstante, encuentra mayores concomitancias con un tapiz con el triunfo de Ceres fechado en 1538 conservado en el Museo Nacional de Baviera, proponiendo la existencia de un prototipo no identificado común para los grabados, el tapiz -al que hay que añadir otro no señalado de la misma serie conservado en el Museo de Detroit y fechado en 1537-1538, esta vez con el triunfo de Flora-y las pinturas murales. Cfr. LLEÓ CAÑAL, Vicente: La Casa de Pilatos..., op. cit., p. 41, nota 104; y LLEÓ CANAL, Vicente: La Casa de Pilatos: biografía..., op. cit., p. 82, nota 194.

${ }^{31}$ Sobre los fundamentos ideológicos de los bienes muebles familiares y la ornamentación de los edificios de la nobleza andaluza del periodo, cfr. URQUÍZAR HERRERA, Antonio: "Masserizia y mayorazgo. La recepción andaluza de las ideas italianas sobre la casa del noble y su adecuación social", en REDONDO CANTERA, María José (coord.): El modelo italiano en las artes plásticas de la península Ibérica durante el Renacimiento. Valladolid, 2004, pp. 195-207; y su posterior estudio: Coleccionismo y nobleza..., op. cit., passim.

${ }_{32}$ El mismo año de su muerte, en 1546, su hijo don Fernando tendría que pleitear con el conde de Castellar debido a que este último estaba construyendo "ciertas cámaras altas e bajas con ciertas ventanas en ellas e corredores de los quales descubre toda la huerta y una sala y un corredor y muchos terrados de las casas principales...”. Cfr. FALCÓN MÁRQUEZ, Teodoro: "El palacio de las Dueñas: sus orígenes...”, op. cit., p. 111; y LLEÓ CAÑAL, Vicente y ASÍN, Luis: El palacio de las Dueñas, op. cit., pp. 56-57. 
antes que de "instrucción". En el ámbito sevillano, solo mucho más tarde, en las pinturas murales de las galerías perimetrales este y oeste del patio bajo del Crucero de los Reales Alcázares se desarrollaría un programa, conservado parcialmente, en el que se representaron por una parte las diferentes actividades de agricultura y ganadería correspondientes a los meses del año, y por otra una serie de escenas de caza y montería; un programa que, aunque diverso en los detalles, participaba de un espíritu en parte análogo ${ }^{33}$.

Un espíritu que, en las casas de doña Inés Portocarrero, habría transformado la tradicional "huerta" en un nuevo espacio idealizado, un locus amoenus. Con esta decoración mural a manera de inmenso telón se trataba de enmascarar el carácter del muro de cerramiento, y la transformación de la huerta de un recinto cerrado, hortus conclusus de tradición medieval e islámica, cercado para flores, árboles frutales y hortalizas, en un espacio conceptualmente abierto y visualmente análogo a una villa rural renacentista. Con todo, aunque podamos apreciar la novedad que representaban estas decoraciones murales en una ciudad en la que continuaban levantándose retablos de estructura arquitectónica tardogótica, no es posible sobrevalorar su valor estético por cuanto, si hemos de juzgar a partir de los escasos y mal conservados ejemplos que han llegado hasta nosotros, no puede decirse que destaquen por su calidad artística. El apresuramiento que se les exigía a los pintores, la falta de incentivos económicos que traían consigo prácticas como las ya citadas subastas a la baja, o condiciones contractuales nunca especialmente favorables para los pintores, no podían contribuir al desarrollo de obras de cierta calidad. En este panorama, la cláusula habitual "muy bien hecho y acabado" parece más una garantía de competencia artesanal que una invitación a la excelencia artística. Por otro lado, a lo largo de toda la primera mitad de la centuria la separación de trabajo fijada en las normas gremiales entre los pintores de las cuatro modalidades establecidas ${ }^{34}$, con algunas excepciones como la de Antón Pérez y quizá la del propio Diego Rodríguez ${ }^{35}$ - fue respetada;

33 A diferencia de las pintadas por Gonzalo Pérez en 1578-1579, hasta el momento no ha sido posible identificar la iconografía de los restos de pinturas murales del sector norte, que no obstante, por razones de estilo, debieron ser realizadas en la primera mitad del siglo. Cfr. BACEIREDO RODRÍGUEZ, $\mathrm{M}^{\mathrm{a}}$ Isabel y BACEIREDO RODRÍGUEZ, Daniel: "Las pinturas murales...", op. cit.; y BACEIREDO RODRÍGUEZ, Ma Isabel: "Intervenciones en las pinturas...", op. cit.

${ }^{34}$ Pintores de imaginería, de decoraciones sobre muro y tabla -policromía de carpinterías-, a los que las ordenanzas sevillanas de 1527 denomina pintores de obra del romano, sargueros y doradores. Cfr. Ordenanças de Sevilla. Sevilla, 1527, editadas en Sevilla, Andrés Grande, 1632, ff. 162-163vto.

35 Aunque todos los conciertos de obra firmados por Rodríguez se refieren a pinturas murales o decorativas, el 5 de agosto de 1544 su viuda e hijo otorgaron un documento inédito según el cual autorizaban a Antonio de Alfián a recibir de Andrés Ramírez seis tableros de pincel que este último se había obligado a pintar a Diego Rodríguez, según un 
como resultado, los que podríamos considerar como pintores de primera fila al parecer se dedicaron de forma casi exclusiva a la pintura de imaginería y no incluyeron en su campo de actividad la pintura mural, aunque esta no deja de ser una hipótesis cuestionable puesto que, como ya insistimos al principio, es muy poco lo que conocemos de las pinturas murales que un día decoraron las casas de los altos estamentos sociales sevillanos ${ }^{36}$. Habría que esperar al regreso a Sevilla del italianizado Luis de Vargas para inaugurar un nuevo periodo en la historia de la pintura mural sevillana del siglo XVI.

Diego Rodríguez es uno de los muy escasos pintores "de obra del romano" de la primera mitad del XVI hispalense cuyo estilo puede ser identificado con alguna seguridad, al haberse conservado, al menos en parte, el ciclo de las Estaciones de la sala de las Vidrieras - hoy conocida como de los Frescos- de la Casa de Pilatos, contratado por don Fadrique en junio de 1539, aunque la existencia de al menos tres conciertos para la obra de pintura no deja de proyectar algunas du$\mathrm{das}^{37}$. El contrato con doña Inés Portocarrero viene a confirmar la sugerencia que se ha avanzado de que los mismos artistas pudieron trabajar en la Casa de Pilatos y el palacio de las Dueñas ${ }^{38}$, aunque no podemos interpretar el hecho de que al año siguiente se hiciera cargo de la decoración mural que nos ocupa como indicio de una especial preferencia por parte de la familia hacia este artista en concreto, en tanto que, al menos en este segundo caso, el pintor se haría cargo de la

contrato notarial que había pasado en Jerez de la Frontera el año anterior. AHPS, sección Protocolos Notariales, leg. 17502, oficio IX, 1544, libro 2, f. 407. Si bien el documento no aclara el destino de estos tableros, habría que tener en cuenta que en fechas cercanas Andrés Ramírez trabajaba junto a su padre Juan Ramírez, Cristóbal de Cárdenas, Antón Pérez, Hernando de Esturmio, Alejo Fernández y Juan de Mayorga en la pintura y dorado del desaparecido retablo mayor de la parroquia de Santiago de Jerez de la Frontera. Cfr. GESTOSO Y PÉREZ, José: Ensayo de un diccionario..., op. cit., t. III, pp. 322-323; y HERNÁNDEZ Díaz, José: "Arte hispalense de los siglos XV y XVI", en D.H.A.A. T. IX. Sevi1la, 1937, pp. 30 y 36 . A pesar de tratarse de un subarriendo de obra, no hay que descartar que Diego Rodríguez pudiera haberse dedicado en algún momento a la pintura de retablos.

${ }^{36} \mathrm{Si}$ tenemos en cuenta la pérdida de la mayor parte de las pinturas murales del periodo, no es extraño que pintores como Alonso Pérez I, Andrés Martín o Alonso Fernández Jurado, abundantemente representados en los registros notariales y que dedicaron su actividad a este campo, sean hoy desconocidos.

${ }^{37}$ La obra la tenía a su cargo Andrés Martín en 1538, quien se comprometía a terminarla en mayo de ese año, pero fue concertada de nuevo por Alonso Hernández Jurado en mayo del año siguiente y pocos días después, en junio, por Diego Rodríguez. ANGULO ÍNIGUEZ, Diego: La mitología..., op. cit., pp. 29-40; SANCHO CORBACHO, Antonio: La cerámica andaluza. Azulejos sevillanos del siglo XVI, de Cuenca. Casa de Pilatos. Sevilla, 1953, p. 11; FALCÓN MÁRQUEZ, Teodoro: "La decoración de los palacios...”, op. cit., pp. 283-284; y LLEÓ CAÑAL, Vicente: La Casa de Pilatos, op. cit., pp. 29 y 35.

${ }^{38}$ FALCÓN MÁRQUEZ, Teodoro: "Palacio de las Dueñas", op. cit., p. 134; y LLEÓ CAÑAL, Vicente: Nueva Roma..., op. cit., p. 36. 
obra después de una subasta a la baja. De esta forma cabe interpretar el último párrafo de las condiciones que, cotejado con otra documentación análoga, indica que una puja de esas características debía seguir a su lectura pública. En principio la subasta sería rematada por Rodríguez, pero desconocemos si llegaría a cumplir la obligación de realizar el notable proyecto de pintura planeado para las casas de doña Inés ${ }^{39}$.

${ }^{39}$ Documentado en Sevilla entre 1528 y 1544, no son muchas las obras conocidas del pintor. Las primeras noticias son de carácter extra artístico, arrendamientos sucesivos de casas en las collaciones de San Miguel y Santa María Magdalena (GESTOSO Y PÉREZ, José: Ensayo de un diccionario..., op. cit., t. III, pp. 292 y 384; y HERNÁNDEZ DÍAZ, José: "Arte hispalense...", op. cit., p. 10), aunque ya en 1529 se obligaba con los pintores Cristóbal de Cárdenas y Andrés Martín para servirles en su oficio de pintor (MURO OREJÓN, Antonio: "Pintores y doradores", op. cit., p. 51). En 1537 firmaría un contrato de servicio con don Baltasar del Río, obispo de Scalas (SANCHO CORBACHO, Heliodoro: "Arte sevillano...", op. cit., p. 18), no concretado, pero que pudo incluir la pintura y dorado de las puertas de los órganos grandes de la catedral, ya que en algunos de los libramientos que se le hicieron respecto a estas en 1538 se especifica como comisario de la obra a don Baltasar (GESTOSO Y PÉREZ, José: Ensayo de un diccionario..., op. cit., t. II, p. 86; y GÓMEZ SÁNCHEZ, Juan Antonio: "Pedro de Campaña en Sevilla. Notas y documentos", Archivo Hispalense, 227, 1991, pp. 121-138). En junio de 1539 firmó el ya citado contrato con don Fadrique Enríquez de Ribera, seguido el año siguiente por el concertado por doña Inés Portocarrero y el ya mencionado para el convento de Santa Inés. Con posterioridad contrataría la ejecución de dos obras hasta el momento desconocidas cuyo análisis posponemos para un estudio ulterior: el 25 de septiembre de 1542 concertó la decoración mural de la puerta de entrada del desaparecido hospital de San Pedro Mártir, siendo fiado por Andrés Martín (AHPS, sección Protocolos Notariales, leg. 13468, oficio XX, 1542, libro 3, s. f.), y el 5 de octubre de ese mismo año las paredes de las casas del jurado Francisco Ruiz en la collación de Santa Catalina, obra esta última que concertó de mancomún con el mismo Martín (AHPS, sección Protocolos Notariales, leg. 13468, oficio XX, 1542, libro 3, f. 913). Diego Rodríguez estuvo casado con Isabel, que consta con el apellido Rodríguez hasta 1536 y posteriormente como de León, habiendo sido vecino sucesivamente de las collaciones de San Miguel, la Magdalena, el Salvador y San Juan de la Palma (GESTOSO Y PÉREZ, José: Ensayo de un diccionario..., op. cit., t. II, p. 86, y t. III, pp. 292, 384 y 415; SANCHO CORBACHO, Heliodoro: "Arte sevillano de los siglos XVI y XVII", en D.H.A.A. T. III. Sevilla, 1931, p. 18; MURO OREJÓN, Antonio: "Pintores y doradores", op. cit., p. 51; y HERNÁNDEZ Díaz, José: “Arte hispalense...”, op. cit., p. 10). En este punto conviene señalar que resulta inexplicable el segundo apellido que se ha aplicado ocasionalmente al pintor, Benamad, apellido que no hemos encontrado en ningún momento en la nueva documentación referida al pintor y que, de hecho, tampoco aparece en el contrato de las pinturas para el marqués de Tarifa, en el que lo cita parte de la bibliografía. Aunque el documento se encuentra en un estado de conservación precario, pensamos que ese segundo apellido se debe a un error de lectura. Por el contrario, aunque en todos los documentos que firmó hizo constar su nombre como Diego Rodríguez, no hay que descartar que haya que identificarlo con el Diego Rodríguez de la Rinconada que 


\section{APÉNDICE DOCUMENTAL}

\section{3-3-1540.}

Diego Rodríguez, pintor, concierta una obra de pintura en las casas de doña Inés Portocarrero.

AHPS (Archivo Histórico Provincial de Sevilla), sección Protocolos Notariales, leg. 17494, oficio IX, 1540, libro 1, registro 27, f. 687.

"Pabto / Diego Rodrigues pintor.

[Las páginas correspondientes al contrato notarial aparecen en blanco.]

En el nonbre de Dios amén.

Esta es una obra de pintura que manda hazer la señora muy magnífica señora la señora doña Ynés Puerto Carrero en las casas de su morada y es la obra una pared que sale a la guerta principal la qual pared es a las espaldas de las casas de su morada y es la obra en esta manera que la dicha pared tiene de canto a canto y de alto a baxo entre tapias y albanerías quatroçientas y cinquenta varas en toda quadra poco más o menos la qual dicha obra a [de] yr traçada en esta manera que se sigue y a de yr pintada en esta manera.

Yten el maestro pintor questa obra tomare a de hazer el primer entabla[mento] junto al tejado dende la una esquina hasta la otra y este entablamento de moldura a de llebar de ancho tres palmos de bara algo más o algo menos segund que a la obra mejor convenga en que en esta cantidad [ha de re]partir las molduras syguientes / junto arriba haga una fre[nte]... [roto] ... de largo a largo y luego haga una cornisa escurreçida por alto e por baxo que haga una folleta abierta y unos gruxos claros y escure[cidos]... [roto] y luego más abaxo una frente de anchura de una pulgada y luego más abaxo dexe otra cantidad al tamaño que convenga benir y haga luego al tamaño que convenga venir unos óbalos a manera que... [roto] ... de a la piedra y luego haga una niçela y luego un festón y luego haga unos canes a manera de dentellones y todas estas maneras tomen este conpás susodicho que tomen estos tres palmos de este entablamento.

Yten el maestro pintor questa obra tomare a de rrepartir en toda esta pared seys rrepartimientos a la luenga en que a de llevar de ancho tres tapias y sy no biniere para rrepartirlo seys tamaños que rreparta quatro o los que mejor vinieren por manera que estos tableros [sean] perlongados y no quadrados y an de ser las figuras como el natural y la primera oherdenansa [sic] a de ser una hordenança de suysos y la otra hordenança a de ser de una[s] caballerías de caballos y la otra hordenança a de ser de mugeres como van caualgan[do] sus... [roto]...s y palafrenes y las otras hordenanças sean... [roto] ... que su merced le mandare / por manera que an de yr asy caballos como hordenanças de suysos como honbres y mugeres

consta como franco de los Alcázares en 1530 (GESTOSO Y PÉREZ, José: Ensayo de un diccionario..., op. cit., t. II, p. 86). 
o hotras qualesquier manera que se ponga a de yr al tamaño del natural por causa del altura y a de yr rrostros y manos y toda la obra de qualquier manera que sea a de yr perfilado al fresco y escurreçido y en algunos cabsos donde más neçeçidad viniere y hará por el suelo algunas piedras e yerbas de prieto. Meterá el canpo de todas las figuras o de otras qualesquier cosas... [roto] ... cantidad e que de razón de suelo de prieto y en medio de cada una ystoria desta y asy mismo a los cabos hará sus pilares quadrados metiéndole dentro unos redondos haziéndole bazas y capiteles y todo esto asy lo uno como lo otro a de quedar bien hecho y bien acabado y no se entiende esto que a de yr a... [roto] ... despejado que se haze syno que a de yr sobre el encalado.

Yten el maestro pintor questa obra tomare a de hazer otro entablamento que tome de largo a largo e que sea menor que el primero medio palmo y a de llevar las mesmas obras que el de arriba lleva salbo que como enprençipia de folleta quenprençipie de óbalos e que lleve sus frentes y sus canes y folletas y todo lo que a una moldura conviene.

Yten el maestro pintor questa obra tomare a de hazer otros tantos rrepartimientos tantos como arriba fuere y en derecho de los pilares de arriba a de hazer sus pilares abaxo que carguen unos en derecho de otros y mire que asy en lo alto como en lo baxo a de hazer sus papos de prietos en que descansan las basas y porque aparte el papo [del] canpo hágale una frente... [roto] ... de tres dedos... [roto] ... tableros an de yr después de sus rrepar[timientos] en cada un tablero an de hazer una hordenança de rromano deferente la una de la otra que lleve muchas deferencias segund que el rromano las trae en que lleve cosas de bivo en que se entiende arpías y niños y golfines y bestiones y otras diferencias que el rromano trae consygo y an de yr asy esto como todo lo demás a de yr ello perfilado de negro y pinseleado y después una aguada muy sotiles parecido[?] en manera que no faga mucha manera y sepa el maestro que esta obra tomare que de alto abaxo por las esquinas hasta el suelo que vaya su rrepartimiento sus pilares como dicho es.

Yten el maestro pintor questa obra tomare a de hazer abaxo destos rromanos otro entablamento como el alto haziéndole todas las obras que los entablamentos llevan y debaxo de este entablamento en derecho de los pilares a de hazer otros pilares abaxo en que alçando del suelo dos palmos de blandos[?] sobre donde binieren los pilares en aquel derecho haga unas basas grandes en que descanse toda la obra y hágales por baxo sus llanos y su frente y arriba otro llano y otra frente y entre basa y basa que se entiende entre pilar e pilar e por lo baxo ponga sus molduras asy por fronteras como por costados y en los espaçios hágales asanefas de rromano conforme a como la obra va.

Yten el maestro pintor questa obra tomare en los espaçios baxos a los de pintar de unos lexos y montaña y a de yr todo esto de prieto e blanco que los... [roto] ... lexos o montañas otras cosas que le pidieren que faga conforme... [roto] ... y segund a buena obra conviene / y toda esta obra no a de llevar otra cosa que los canpos donde les convenga y todo lo baxo que se entiende en los suelos a de yr 
labrado a manera de suelo todo e dende lo mayor a lo menor a de yr muyn [sic] byen hecho y acabado a vista de ofiçiales sabidores del dicho ofiçio.

Yten el maestro pintor questa obra tomare a de poner todo lo que en ella fuere menester asy de color como de ofiçiales como de otros materiales que fueren menester y el señor de la obra le a de mandar e dar andamyos a su contento y se entiende que a de hazer con los andamios que el maestro albañil hiziere y a de contentar de fianças al señor de la obra dentro del tercer día primero syguiente y dende a la ora que la obra se rematare se obligue a la hazer y conplir y sy no contentare al señor de la obra que pague myll maravedís de pena para ell [sic] otro que atrás viniere y la obra fiançare y asy mesmo su merced mandará dar los maravedís por sus tercias el primero luego en fiançando la obra y el segundo estando demediada y el tercero para acabar la obra.

Yten el maestro pintor questa obra tomare de al maestro questa obra [sic] de dos ducados y medio y otros dos ducados y medio a los ofiçiales questuvieron al remate y hizieron las condiçiones y con estas condiçiones la puso Alonso Péres en veynte myll maravedís."

Firmado: Diego Rodríguez, pintor, y los escribanos Alonso de Baena, Juan de Vergara y Juan de Velarte.

Fecha de recepción: 30 de octubre de 2018

Fecha de aceptación: 1 de julio de 2019 


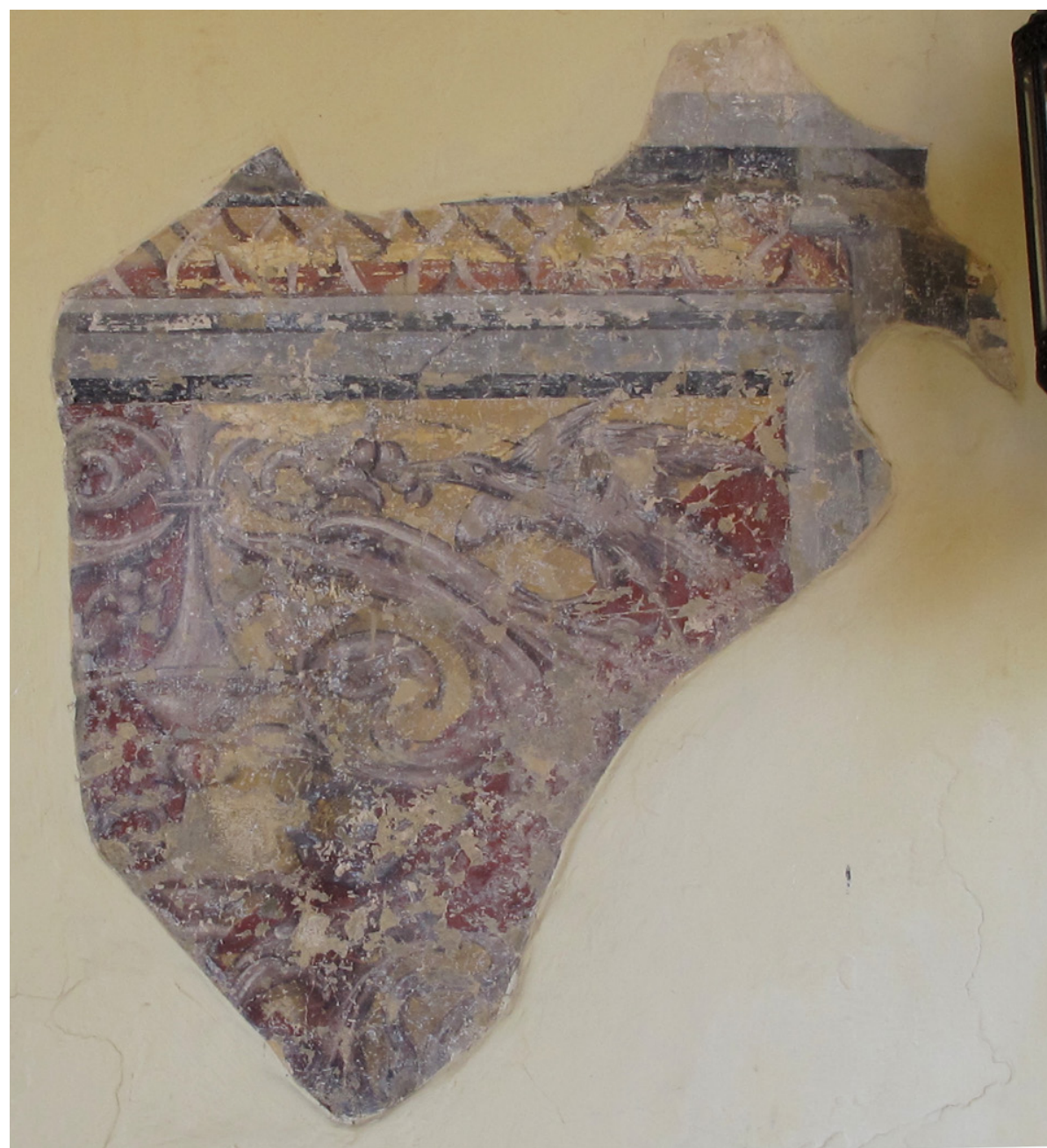

Figura 1. Fragmento de pintura mural, muro norte de la galería alta del patio principal, palacio de las Dueñas, Sevilla. Foto: Juan Antonio Gómez Sánchez. 


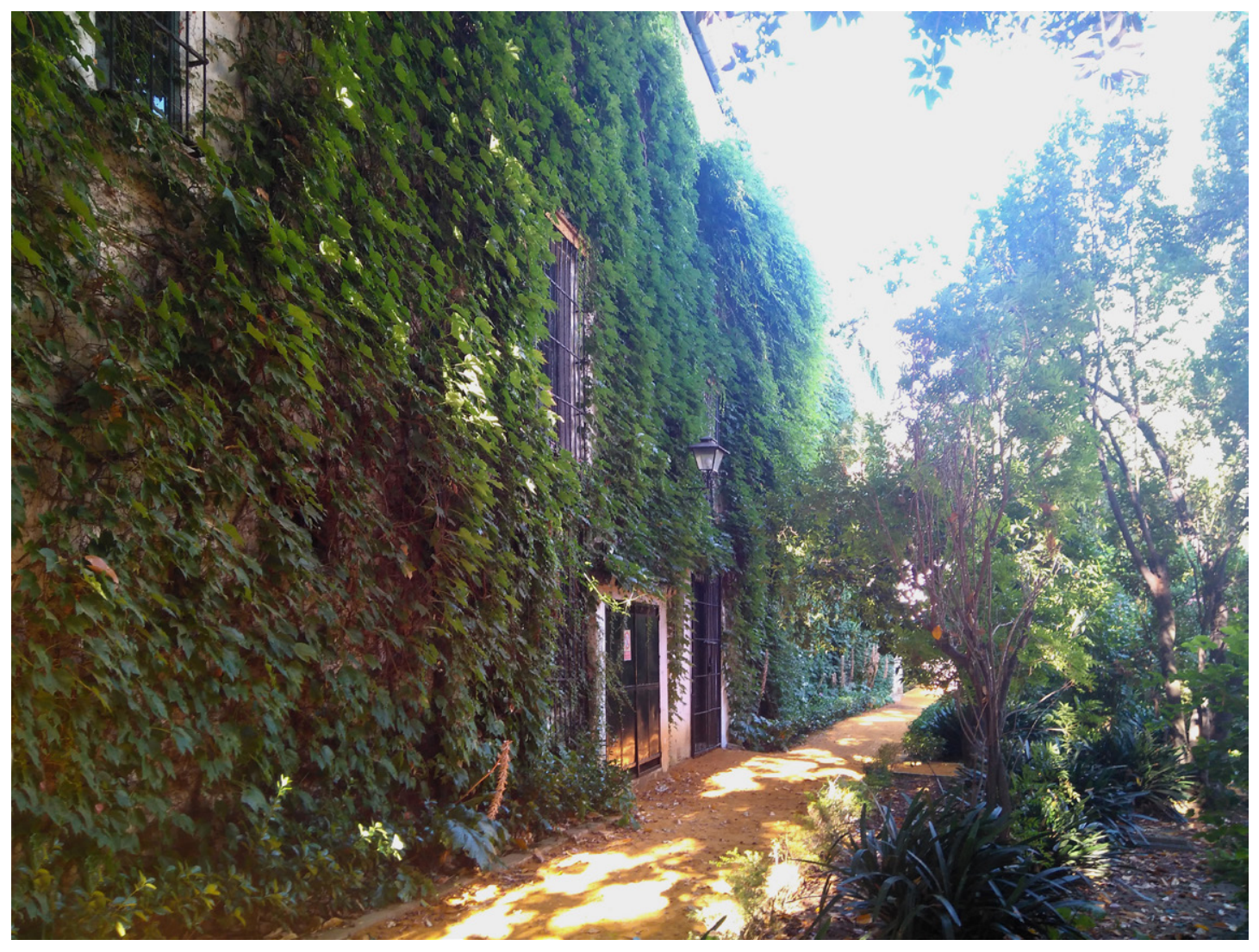

Figura 2. Muro de cierre del sector norte, palacio de las Dueñas, Sevilla. Foto: Pilar Rodríguez Moreno. 


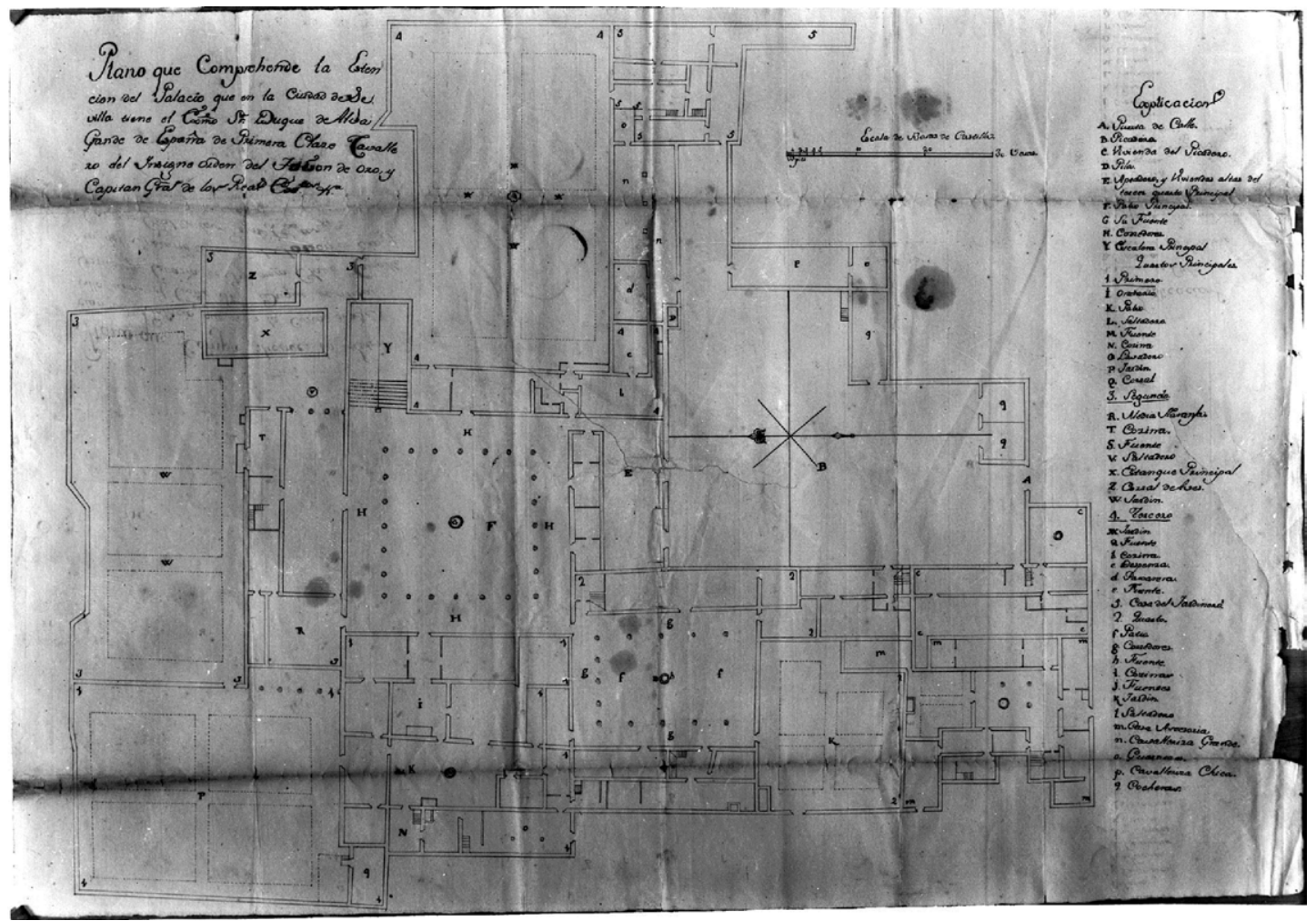

Figura 3. Plano del Palacio de las Dueñas, 1756, paradero desconocido. Foto: Antonio Sancho, SGI Fototeca-Laboratorio de Arte de la Universidad de Sevilla, reg. 4-2172. 


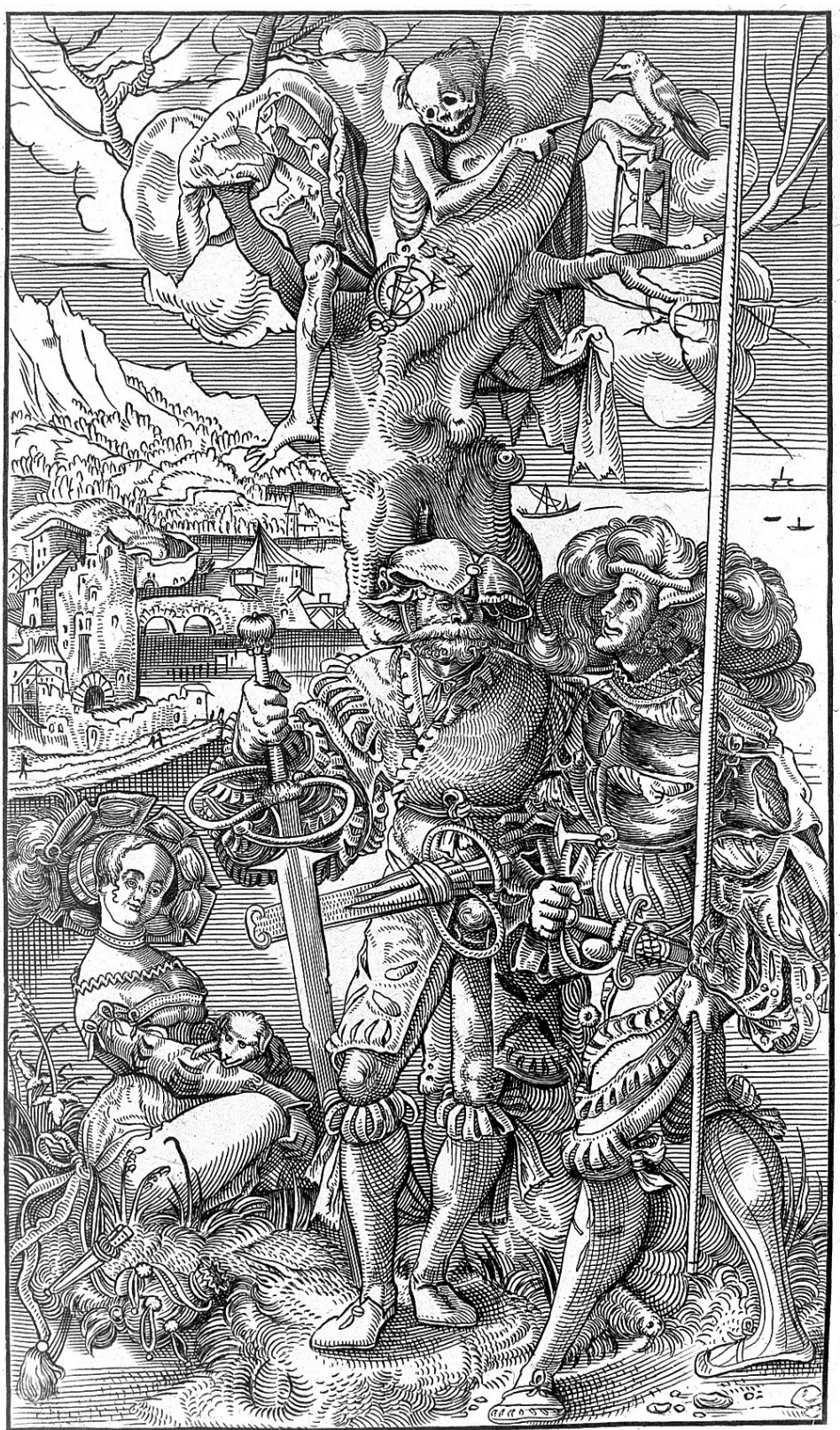

Figura 4. Urs Graf, Lansquenete (en el centro), reisläufer (mercenario suizo, a la derecha), una prostituta y la muerte, grabado, 1524.

Foto: Wellcome Collection. 